OPEN ACCESS

Edited by:

Esther M. Lafuente,

Complutense University of Madrid,

Spain

Reviewed by:

Soldano Ferrone,

Massachusetts General Hospital and Harvard Medical School,

United States

Patricia A. Possik,

Instituto Nacional de Câncer

(INCA), Brazil

${ }^{*}$ Correspondence:

Jessica Dal Col

jdalco/@unisa.it

tThese authors share last authorship

Specialty section

This article was submitted to Cancer Immunity and Immunotherapy,

a section of the journal

Frontiers in Immunology

Received: 01 October 2019 Accepted: 23 December 2019 Published: 31 January 2020

Citation:

Nigro A, Ricciardi L, Salvato I, Sabbatino F, Vitale $M$, Crescenzi MA,

Montico B, Triggiani M, Pepe S,

Stellato C, Casolaro V and Dal Col J (2020) Enhanced Expression of CD47

Is Associated With Off-Target

Resistance to Tyrosine Kinase Inhibitor

Gefitinib in NSCLC.

Front. Immunol. 10:3135

doi: 10.3389/fimmu.2019.03135

\section{Enhanced Expression of CD47 Is Associated With Off-Target Resistance to Tyrosine Kinase Inhibitor Gefitinib in NSCLC}

\author{
Annunziata Nigro ${ }^{1}$, Luca Ricciardi ${ }^{1}$, llaria Salvato ${ }^{1}$, Francesco Sabbatino ${ }^{1}$, Monica Vitale ${ }^{1}$, \\ Maria Assunta Crescenzi ${ }^{1}$, Barbara Montico ${ }^{2}$, Massimo Triggiani ${ }^{1}$, Stefano Pepe ${ }^{1}$, \\ Cristiana Stellato ${ }^{1}$, Vincenzo Casolaro ${ }^{1+}$ and Jessica Dal Col ${ }^{1 * t}$ \\ 1 Department of Medicine, Surgery and Dentistry "Scuola Medica Salernitana," University of Salerno, Baronissi, Italy, \\ ${ }^{2}$ Immunopathology and Cancer Biomarkers, Translational Unit, Centro di Riferimento Oncologico di Aviano (CRO), IRCCS, \\ Aviano, Italy
}

Mutual interactions between cancer cells and the tumor microenvironment importantly contribute to the development of tyrosine kinase inhibitor (TKI) resistance in patients affected by EGFR-mutant NSCLC. In particular, immune recognition-associated proteins with impact on tumor cell clearance through phagocytosis, such as CD47 and calreticulin, could contribute to adaptive resistance and immune escape. Preclinical studies targeting the anti-phagocytic CD47 molecule showed promising results in different cancer types including lung cancer, but no data are available on its role in patients acquiring resistance to EGFR TKI treatment. We analyzed the functional contribution of CD47 and calreticulin to immune surveillance and evasion in a panel of NSCLC cell lines carrying sensitizing or resistant mutations in the EGFR gene, following treatment with the TKI gefitinib and after in vitro development of gefitinib resistance. While CD47 and calreticulin protein levels were markedly variable in both EGFR-mutant and wild-type cell lines, analysis of NSCLC transcriptomic dataset revealed selective overexpression of CD47 in patients carrying EGFR mutations. EGFR inhibition significantly reduced CD47 expression on the surface of pre-apoptotic cells, favoring more efficient engulfment of cancer cells by monocyte-derived dendritic cells. This was not necessarily associated with augmented surface exposure of calreticulin or other molecular markers of immunogenic cell death. Moreover, CD47 expression became up-regulated following in vitro drug resistance development, and blocking of this protein by a specific monoclonal antibody increased the clearance of EGFR-TKI resistant cells by phagocytes. Our study supports CD47 neutralization by specific monoclonal antibody as a promising immunotherapeutic option for naïve and resistant EGFR-mutant NSCLCs.

Keywords: CD47, non-small cell lung cancer, tyrosine kinase inhibitor resistance, phagocytosis checkpoint, innate immunity, cancer immune surveillance 


\section{INTRODUCTION}

Non-small-cell lung cancer (NSCLC) accounts for $85 \%$ of all diagnosed cases of lung cancers, with the diagnosis taking place often when the disease is at locally advanced or metastatic stage $(1,2)$. The discovery of oncogenic driver mutations in almost two-thirds of NSCLCs and the introduction of targeted therapies undeniably improved the outcome in patients with oncogene-addicted adenocarcinoma. However, clinical response to treatment is generally temporary and incomplete (3). Recent studies on the molecular determinants of resistance to tyrosine kinase inhibitors (TKIs) identified two major mechanisms either affecting targeted oncogenes ("on-target" resistance) or molecules residing downstream or belonging to parallel and other pathways ("off-target" resistance) (4). In addition, dynamic interactions between tumor cells and the surrounding microenvironment critically contribute to modifying the response to TKI therapy and influence the development of resistant phenotypes (5-7). It has been demonstrated that in epidermal growth factor receptor (EGFR)driven lung tumors, anti-tumor immunity is inhibited by activation of the Programmed death 1 (PD-1)/Programmed death ligand 1 (PD-L1) pathway, leading to suppression of effector T cell function and increased levels of pro-inflammatory cytokines (8). As recently shown, PD-L1 expression in tumor cells adversely affects EGFR-TKI efficacy, especially in NSCLC patients with de novo resistance (9). Furthermore, the secretion from stromal cells of paracrine factors such as interleukin-6 (IL-6), transforming growth factor- $\beta$ (TGF- $\beta$ ), and hepatocyte growth factor (HGF) promotes MAP-kinase activation and further supports EGFR TKI resistance development by eluding EGFR pathway inhibition (10).

Immune checkpoint inhibitors (ICIs) targeting the PDL1/PD-1 axis have been recently approved for the treatment of EGFR- and Anaplastic lymphoma kinase (ALK)-positive NSCL tumors after failure of appropriate targeted therapy $(11,12)$. While the association of EGFR mutations with high PD-L1 expression suggests the potential efficacy for PD-L1 inhibitors in this setting, treatment with ICIs showed limited efficacy in different cohorts of patients previously treated with an EGFR TKI (13-16) and the outcome did not show correlation with the EGFR mutation subtype. The poor response to ICIs in EGFRmutated, TKI-resistant patients suggests that other immuneescape mechanisms are at stake in this clinical phenotype.

No studies to date have examined the effects of EGFR TKIs on immune recognition-associated molecules, such as CD47 and calreticulin (CRT), recently found to affect innate immune surveillance. CD47, originally identified as integrin-associated protein (IAP), is a cell-surface immunoglobulin-like molecule that serves as a "don't eat me" signal via its interaction with signal regulatory protein alpha $(\operatorname{SIRP} \alpha)$ on phagocytes $(17,18)$. Loss of CD47 is permissive to homeostatic phagocytosis of aged or damaged cells $(19,20)$. While CD47 is ubiquitously expressed at low levels on normal cells, multiple hematologic and solid tumors have been found to express higher levels of CD47 compared to their non-transformed counterparts (21-24). Enhanced expression of CD47 has also been reported in primary NSCLC tumors and cell lines (25). Up-regulation of CD47 expression in human cancers negatively regulates anti-tumor immunity through suppression of phagocytosis, and it has been associated with tumor growth and dissemination $(18,25-28)$. Conversely, CRT is a highly conserved endoplasmic reticulum chaperone protein, which, upon translocation from the endoplasmic reticulum to the cell surface, provides an "eat-me" signal and facilitates capture by macrophages and dendritic cell precursors of cancer cells undergoing immunogenic cell death (ICD) or other stress conditions $(29,30)$. Fucikova et al. demonstrated that the expression of CRT in NSCLC correlates with increased accumulation of antitumor immune cells and favorable prognosis (31). Given the emerging critical roles of CD47 and CRT in NSCLC adenocarcinomas, in the present study, we assessed whether the EGFR TKI gefitinib modulates their expression in different EGFR-mutated NSCLCs. Furthermore, we analyzed in these cells the functional contribution of these proteins to immune surveillance, while their potential role in surveillance evasion was tested in subsets of NSCLC cell lines rendered TKI resistant in vitro.

\section{MATERIALS AND METHODS}

\section{Cell Lines}

Human NSCLC cell lines NCI-H1975, NCI-H1299, NCI-H1437, and NCI-H1573 were purchased from ATCC (American Type Culture Collection, Manassas, Virginia). PC9 and HCC827 cell lines were obtained from Cell Biology and Biotherapy Unit, Istituto Nazionale Tumori di Napoli, IRCCS "G. Pascale." The EGFR TKI-resistant cell lines, PC9GR and HCC827GR, were generated by culturing the respective parental cell lines in the presence of increasing concentrations of TKI Gefitinib (from 0.05 to $0.5 \mu \mathrm{M}$ and from 0.1 to $1 \mu \mathrm{M}$, respectively) for 8 weeks, to reach a concentration 10 times higher than the initial $\mathrm{IC}_{50}$. Cell lines were cultured in RPMI-1640 medium (Gibco) supplemented with 10\% fetal bovine serum (Gibco), $1 \%$ L-glutamine (2 $\mathrm{mM}$, Lonza), $1 \%$ streptomycin-penicillin (EuroClone) at $37^{\circ} \mathrm{C}$ in a $5 \% \mathrm{CO}_{2}$ humidified atmosphere. Short tandem repeat (STR) loci for cell lines authentication were evaluated for all cell lines, by using the GenePrint10System (Promega).

\section{Antibodies and Reagents}

Anti-CD47-APC, anti-CD47-FITC, anti-CD11c-APC-Vio770, anti-CD11-PE, anti-CD14-FITC, anti-CD80-PE, anti CD83-PE, anti-CD86-PE, anti-HLA-DR-FITC, anti-HLA-ABC-FITC, antiHsp70-FITC, and 7-Amino-Actinomycin D (7-AAD) fluorescent DNA dye were purchased from Miltenyi. All monoclonal antibodies (mAbs) used in flow cytometry experiments were used at 1:200 titer unless otherwise specified. Anti-calreticulinFITC mAb (EPR3924; 1:50) and anti-GAPDH were from Abcam. Anti-mouse/human/rat CD47 $\mathrm{mAb}$ or mouse IgG isotype control were purchased from Bio X Cell. Anti-phospho-EGFR (Y1608), anti-EGFR, and anti-phospho-Akt (S473) were from Cell Signaling Technology. Secondary antibodies anti-rabbit IgGHRP or anti-mouse IgG+IgM+IgA-HRP were from Bethyl Laboratories. Gefitinib was purchased from Selleckchem, and 
its $\mathrm{IC}_{50}$ was determined for each cell line using Cell-Counting Kt-8 (Dojindo Laboratories) according to the manufacturer's instructions. Gefitinib $\mathrm{IC}_{50}$ for each cell line, reported in Table 1, was used for all the experiments. Recombinant human granulocyte-macrophage colony-stimulating factor (GM-CSF) was purchased from Miltenyi, and interferon (IFN)- $\alpha$ (IntronA) from SP Europe.

\section{Protein Extraction and Western Blot}

For total protein extraction, cells were directly lysed in a buffer containing $50 \mathrm{mM}$ Tris/ $\mathrm{HCl}$ at $\mathrm{pH} 7.5,150 \mathrm{mM} \mathrm{NaCl}, 2 \mathrm{mM}$ EDTA, 2 mM EGTA, $25 \mathrm{mM} \mathrm{NaF}, 25 \mathrm{mM} \beta$-glycerolphosphate, $0.1 \mathrm{mM} \mathrm{Na} \mathrm{VO}_{4}, 0.1 \mathrm{mM}$ PMSF, $0.2 \%$ Triton X-100, $0.3 \%$ Nonidet P40, and a cocktail of protease inhibitors (100 X, EuroClone). After incubation on ice for $30 \mathrm{~min}$, the lysate was centrifuged at $13,000 \mathrm{rpm}$ for $15 \mathrm{~min}$ at $4^{\circ} \mathrm{C}$. A total of $15 \mu \mathrm{g}$ of protein per well was separated by $4-15 \%$ sodium dodecyl sulfate-polyacrylamide gel electrophoresis and transferred to nitrocellulose membranes. Membranes were then blocked with $5 \%$ milk-TBST buffer (TBS plus $0.1 \%$ Tween-20) for $1 \mathrm{~h}$ at room temperature and incubated with primary antibodies overnight at $4^{\circ} \mathrm{C}$, washed with TBST buffer three times, and incubated with corresponding secondary antibodies at room temperature for $45 \mathrm{~min}$. Signals were detected by the "Pierce ECL Western Blotting Substrate" method (Thermo Fisher Scientific) and analyzed by the ImageLab software, using the Chemidoc image acquisition and analysis tool (BioRad).

\section{Flow Cytometry Analysis}

To measure the cell surface expression of CD47 and CRT, $2.5 \times$ $10^{5}$ cells were seeded in 6-well plates and treated with gefitinib at their specific $\mathrm{IC}_{50}$ (see Table $\mathbf{1}$ ) or corresponding proportions of DMSO solvent for $48 \mathrm{~h}$. Cells were stained with primary antibodies for $20 \mathrm{~min}$ at room temperature (RT). Seven-AAD was added to exclude non-viable cells from the analyses. For intracellular labeling with anti-CD47-FITC mAb, cells were fixed with $4 \%$ paraformaldehyde (PFA) and permeabilized with $100 \%$ cold methanol. Cells were acquired using a BD FACSVerse ${ }^{\mathrm{TM}}$ flow cytometer (BD Biosciences) and the data were analyzed using the BD FACSuite ${ }^{\mathrm{TM}}$ software.

\section{Differentiation of Dendritic Cells From CD14+ Monocytes Isolated From Peripheral Blood}

Human peripheral blood mononuclear cells (PBMCs) were isolated from whole blood donated by healthy volunteers using Ficoll HyPaque (GE Healthcare). Monocytes were isolated from PBMCs by positive selection onto MACS LS columns using CD14 MicroBeads (Miltenyi) following the manufacturer's protocol. The resulting cell suspensions, containing at least $85 \%$ monocytes, were seeded in 6-well plates at a concentration of $2.0 \times 10^{6}$ cells $/ \mathrm{ml}$ and cultured for 3 days at $37^{\circ} \mathrm{C}$ in a $5 \%$ $\mathrm{CO}_{2}$ humidified atmosphere in CellGenixTM GMP DC medium (CellGenix $\mathrm{GmbH}$ ) supplemented with $1 \%$ streptomycinpenicillin (EuroClone), and in the presence of $500 \mathrm{ng} / \mathrm{ml} \mathrm{GM-}$ $\mathrm{CSF}$ and $10,000 \mathrm{U} / \mathrm{ml} \mathrm{IFN}-\alpha$ (32). Differentiation of dendritic cells was confirmed by immune phenotype analysis for the established dendritic cell markers: CD80, CD83, CD86, CD11c, and HLA-DR.

\section{In vitro Phagocytosis Assay}

Dendritic cells were plated in 24 -well plates $\left(10^{5}\right.$ cells/well $)$. After $48 \mathrm{~h}$, lung tumor cells treated with gefitinib at their specific $\mathrm{IC}_{50}$ (see Table 1) or DMSO carrier were labeled with DiO cell-labeling solution (Vybrant Cell-Labeling Solution, Molecular Probes) and added to dendritic cells at a 1:1 ratio. Where indicated, tumor cells were incubated with antimouse/human/rat CD47 mAb $(10 \mu \mathrm{g} / \mathrm{ml}$, Bio X Cell) or mouse IgG isotype control $(10 \mu \mathrm{g} / \mathrm{ml}$, Bio X Cell $)$ prior to culture with dendritic cells. Following $2.5 \mathrm{~h}$ co-culture at $37^{\circ} \mathrm{C}$, cells were washed twice with PBS and then labeled with anti-CD11c

\begin{tabular}{|c|c|c|c|c|c|c|}
\hline PC9 & $\begin{array}{l}\text { NSCLC } \\
\text { adenocarcinoma }\end{array}$ & Primary & EGFR & E746-A750 deletion & Activating, biomarker for TKI therapy & $\mathrm{IC}_{50}=0.05 \mu \mathrm{M}$ \\
\hline HCC827 & $\begin{array}{l}\text { NSCLC } \\
\text { adenocarcinoma }\end{array}$ & Primary & EGFR & E746-A750 deletion & Activating, biomarker for TKI therapy & $\mathrm{IC}_{50}=0.1 \mu \mathrm{M}$ \\
\hline H1299 & $\begin{array}{l}\text { NSCLC } \\
\text { large-cell carcinoma }\end{array}$ & $\begin{array}{l}\text { Metastasis, } \\
\text { lymph node }\end{array}$ & $\begin{array}{l}\text { NRAS } \\
\text { TP53 }\end{array}$ & WT & & $\mathrm{IC}_{50}>15 \mu \mathrm{M}$ \\
\hline $\mathrm{H} 1437$ & $\begin{array}{l}\text { NSCLC } \\
\text { adenocarcinoma }\end{array}$ & $\begin{array}{l}\text { Metastasis, } \\
\text { pleural } \\
\text { effusion }\end{array}$ & $\begin{array}{l}\text { CDKN2A } \\
\text { TP53 }\end{array}$ & WT & & $\mathrm{IC}_{50}>15 \mu \mathrm{M}$ \\
\hline
\end{tabular}

The indicated gefitinib $I_{5}$ values were measured experimentally. 
mAbs (1:200, Miltenyi). Phagocytosis was determined by flow cytometry detection of dendritic cells double positive for CD11c and $\mathrm{DiO}$ cell-labeling solution.

\section{Annexin V/PI Apoptosis Assay}

Tumor cells were seeded into 6 -well plates $\left(2.5 \times 10^{5}\right.$ cells per well) and cultured $(72 \mathrm{~h})$ in the absence or presence of gefitinib at their specific $\mathrm{IC}_{50}$ (see Table 1). Apoptosis was assessed by cytofluorimetric analysis using FITC-Annexin V Apoptosis Detection Kit (Dojindo Laboratories) according to the manufacturer's instructions.

\section{Analysis of CD47 and CRT mRNA in Transcriptomic Databases of NSCL Adenocarcinomas}

CD47 and CRT mRNA expression was determined in a publicly available microarray database collecting frozen primary NSCLC specimens with different oncogenic driver mutations (GEO accession number GSE31210) $(33,34)$. Only the Jetset best probe sets were considered (35), 226016_at for CD47 and 214315_x_at for CRT.

\section{Statistical Analysis}

Protein expression levels of CD47 and CRT in the different cell lines were compared using ANOVA test with Fisher's post hoc multiple comparison analysis, whereas mRNA expression levels in different groups of patients were compared using the nonparametric Kruskal-Wallis test. The effect of gefitinib on CD47 and CRT surface expression and on phagocytosis was determined by two-tail paired Student's $t$-test, based on a minimum of three experiments/different donors. The effect of a CD47-neutralizing antibody on phagocytosis was determined using ANOVA test with Fisher's post hoc multiple comparison analysis. Statistical analysis was performed using GraphPad Prism 5 (GraphPad Software, Inc. La Jolla, CA, USA).

\section{RESULTS}

\section{Treatment With Gefitinib Modulates CD47 and CRT Surface Expression in NSCLC Cell Lines}

The basal expression levels of CD47 and surface-exposed CRT (ecto-CRT) were investigated in a panel of six NSCLC cell lines harboring different mutations on EGFR as well as on other genes connected or not to the EGFR pathway (Table 1). Flow cytometry analysis showed that expression levels of surface CD47 and ectoCRT are markedly variable among the different cell lines and independent of the type of EGFR mutations (Figures 1A,B). Retrospective analysis of a published dataset of microarray expression data from frozen primary lung adenocarcinoma specimens allowed us to investigate CD47 and CRT mRNA levels in patients $(N=226)$ with different oncogenic driver mutations (GEO accession number GSE31210) $(33,34)$. As shown in Figure 1C, patients with EGFR mutations expressed higher levels of CD47 mRNA compared to patients with KRAS mutations, ALK-fusion, or no mutations in these three driver oncogenes
(Figure 1C, $p \leq 0.03$ Kruskal-Wallis test). In contrast, in the same dataset, CRT mRNA expression showed no significant differences among the four groups of patients (Figure 1D).

Next, we assessed the ability of gefitinib to modulate CD47 and CRT surface expression in the cell lines tested. Cells were cultured for $48 \mathrm{~h}$ with gefitinib concentrations corresponding to $\mathrm{IC}_{50}$ identified for each cell line (listed in Table 1) or an equivalent DMSO amount. Immunoblotting analysis of phospho-EGFR confirmed the inhibition of EGFR activating phosphorylation by gefitinib (Figure S1). Flow cytometry analysis of viable cells showed that gefitinib significantly down-regulated CD47 surface expression in all cell lines, except for HCC827, one of the two cell lines harboring the EGFR exon 19 deletion (del19 mutation) (Figures 2A,C). Concomitantly, gefitinib treatment promoted a significant increase of ecto-CRT expression in all cell lines carrying wild-type EGFR and in H1975, whereas no significant difference was induced in HCC827 and a slow, but consistent ecto-CRT reduction was detected in PC9 cells (Figures 2B,D).

\section{Gefitinib-Induced Modulation of CD47 and CRT Is Independent on Immunogenic Cell Death Promotion}

Previous work has shown that the anti-EGFR mAb cetuximab induces immunogenic cell death (ICD) in colon cancer cells by triggering endoplasmic reticulum stress response and CRT translocation, depending on the mutational status of the EGFR signaling pathway (36). Therefore, we next investigated if the effects of gefitinib on CD47 and ecto-CRT expression were associated to the induction of ICD in NSCLC cells. The markers of ICD evaluated together with the ecto-CRT expression were the induction of apoptosis, the surface exposure of CRT heatshock protein 70 (HSP70), and the release of HSP70 and of high mobility group box-1 (HMGB1) (37). Consistently with the spatiotemporal sequence of ICD markers, surface exposure of proteins was measured in pre-apoptotic cells after $48 \mathrm{~h}$ of treatment, whereas the release of HSP70 and HMGB1 was measured $72 \mathrm{~h}$ after treatment. As shown in Figures $3 \mathbf{A}, \mathbf{B}$, treatment with gefitinib significantly increased the frequency of cells undergoing apoptosis relative to DMSO-treated cells. Moreover, gefitinib increased the surface expression of HSP70 by $\geq 50 \%$ in all cell lines except in cell lines carrying EGFR exon 19 deletion, PC9, and HCC827 (Figures 3C,D), in agreement with findings on ecto-CRT expression in these two cell lines (Figures 2B,D). In contrast, as shown in Figure 3E, gefitinib increased HSP70 release over control-treated cells only in the PC9 cell line. Lastly, gefitinib-induced apoptosis was not associated with HMGB1 release, which was not detected in supernatants (data not shown).

Taken together, these results, summarized in Figure 3F, indicate that while gefitinib-promoted apoptosis is associated with several ICD traits, these are not all detectable in each cell line. Therefore, according to recently published findings (38), the results indicate that EGFR inhibition by gefitinib does not induce ICD in the NSCLC cell lines tested. Moreover, even the concomitant activation of the type I interferon pathway, a well-known important mediator of ICD (39), was insufficient 

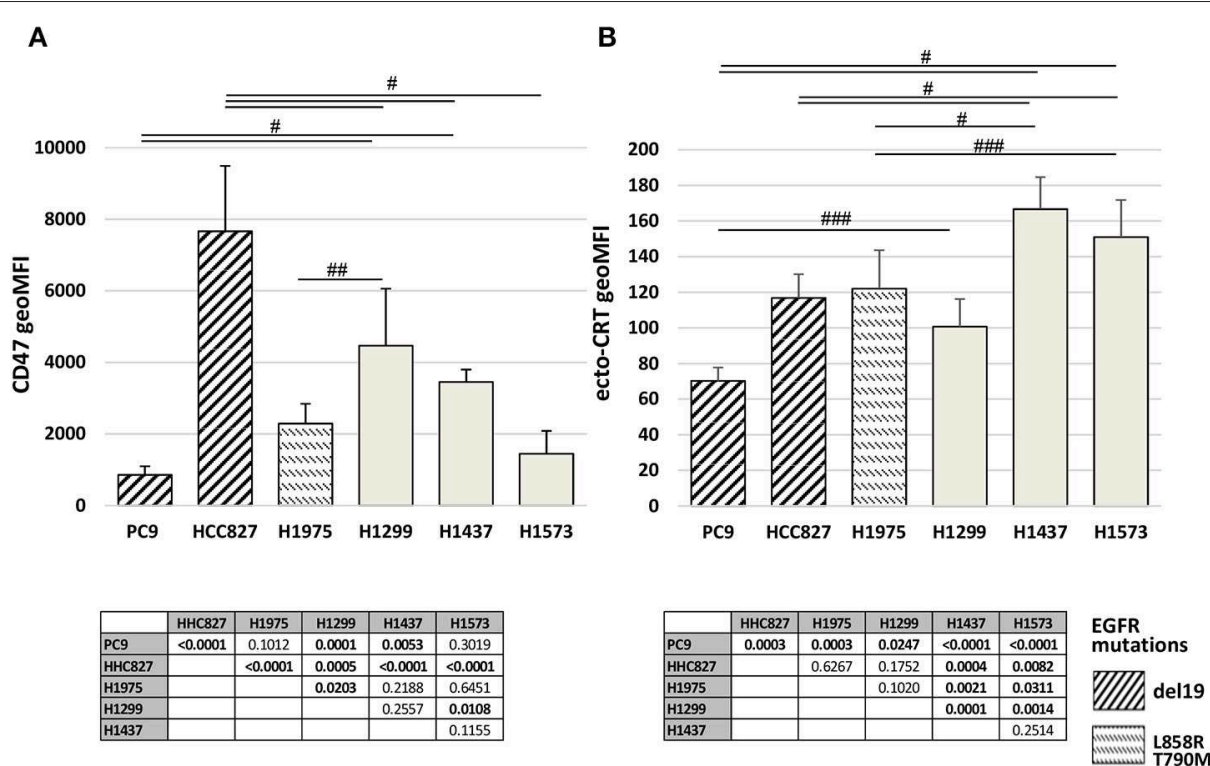

C

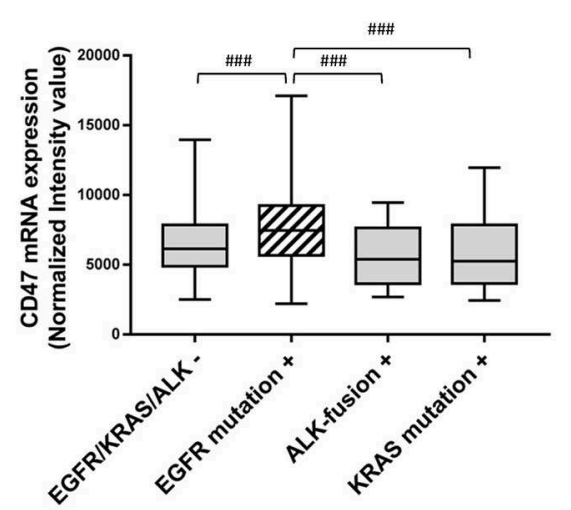

D

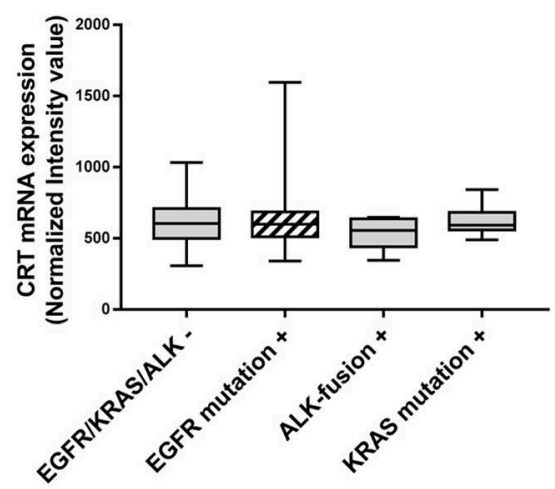

FIGURE 1 | Surface CD47 and CRT expression in EGFR wild-type and mutant NSCLC cells. Surface CD47 (A) and ecto-CRT protein expression (B) shown as geometric MFI in a panel of six different NSCLC cell lines. Each histogram represents the mean ( \pm SD) of three to five independent experiments. Comparisons made by ANOVA with Fisher's post hoc multiple comparison analysis. $\# \# \# p<0.03, \# \# p<0.01, \# p<0.0005$. Below each histogram, a matrix table where all $p$ values resulting from post hoc analysis are reported. Expression levels of CD47 (C) and CRT mRNA (D) in 226 untreated primary NSCL adenocarcinomas (GEO accession number GSE31210). Middle lines in box plots represent the medians and whiskers represent 5-95\% Cl (\#\#\# $p<0.03$, Kruskal-Wallis test).

to induce ICD in these experiments. In fact, the addition of IFN- $\alpha$ in these cultures, while further increasing the frequencies of apoptotic cells, did not augment the effects of gefitinib on CD47 and ecto-CRT expression (Figures S2A-C) and was also insufficient to induce HMGB1 release (data not shown).

\section{Gefitinib-Induced CD47 Down-Regulation Promotes Phagocytosis of Tumor Cells by IFN-Conditioned Dendritic Cells}

Since the balance between CD47 and ecto-CRT expression determines the susceptibility of cancer cells to engulfment by phagocytes, based on our results (Figures 2C,D), we hypothesized that gefitinib treatment could promote phagocytosis of NSCLC cells by CD47 down-regulation. To test our hypothesis, we performed phagocytosis assay using monocyte-derived dendritic cells from healthy donors and, as target cells, we selected PC9, HCC827, and H1975 cell lines cultured in the presence of gefitinib or DMSO for $48 \mathrm{~h}$. These cell lines were included because of their differential mutational status (EGFR del19 mutation and gefitinib resistant T790M mutation, respectively) and of their differential CD47/ecto-CRT balance following treatment with gefitinib. Cell incubation time was kept at $48 \mathrm{~h}$, since at this time point CD47 down-regulation and ecto-CRT increase were detectable without high levels of apoptosis. Gefitinib-treated and untreated cells were then labeled with the fluorescent tracer $\mathrm{DiO}$ (see Methods) and then cocultured for $2 \mathrm{~h}$ with monocyte-derived dendritic cells $(29,40)$. As shown in Figures 4A,B, PC9 cells treated with gefitinib were 


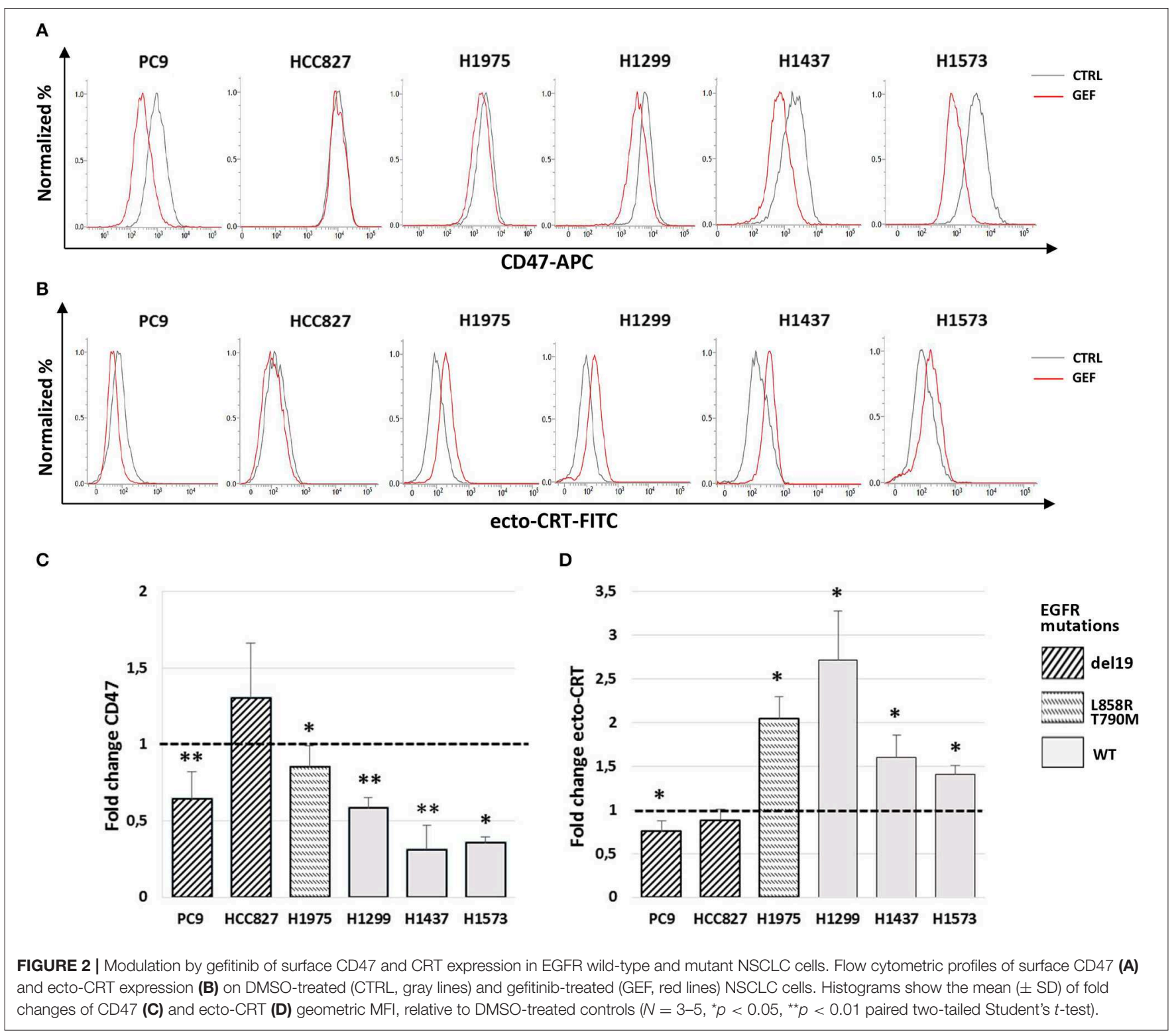

engulfed more efficiently than untreated controls, in line with the significant down-regulation of CD47 induced by gefitinib in these cells (Figures 2A,C). Conversely, gefitinib treatment did not significantly affect HCC827 and H1975 cell uptake by dendritic cells (Figures 4C-F). These findings indicate that the marked ecto-CRT up-regulation observed in gefitinib-treated H1975 cells (Figures 2B,D) is not sufficient to increase cell susceptibility to phagocytosis in the absence of a substantial decrease of CD47 (Figures 2A,C).

Indeed, the addition of a CD47-specific blocking $\mathrm{mAb}$ to gefitinib-treated or untreated HCC827 and H1975 cells significantly increased the percentage of DiO-positive dendritic cells, while addition of an isotype control did not affect tumor cell engulfment (Figures 5A,B). This indicates that down-regulation of $\mathrm{CD} 47$ in gefitinib-treated NSCLC cells is per se sufficient to enhance antitumor immunity by improving cell recognition and engulfment by immune phagocytes.

\section{CD47 Expression Increases in NSCLC Cells Acquiring Gefitinib Resistance in vitro}

The development of TKI resistance is the main limiting factor of this otherwise effective target therapy in patients affected by EGFR-mutant lung cancer. Given the increasing evidence of the involvement of tumor microenvironment in remodeling cancer cell responsiveness to TKI therapy, we investigated the expression of CD47 and ecto-CRT in PC9 and HCC827 cell lines after the acquisition of gefitinib resistance in vitro. Gefitinib-resistant PC9GR and HCC827GR cells were generated upon exposure to gradually increasing concentrations of the drug. Flow cytometry analyses showed a significant increase of surface CD47 expression in both PC9GR and 


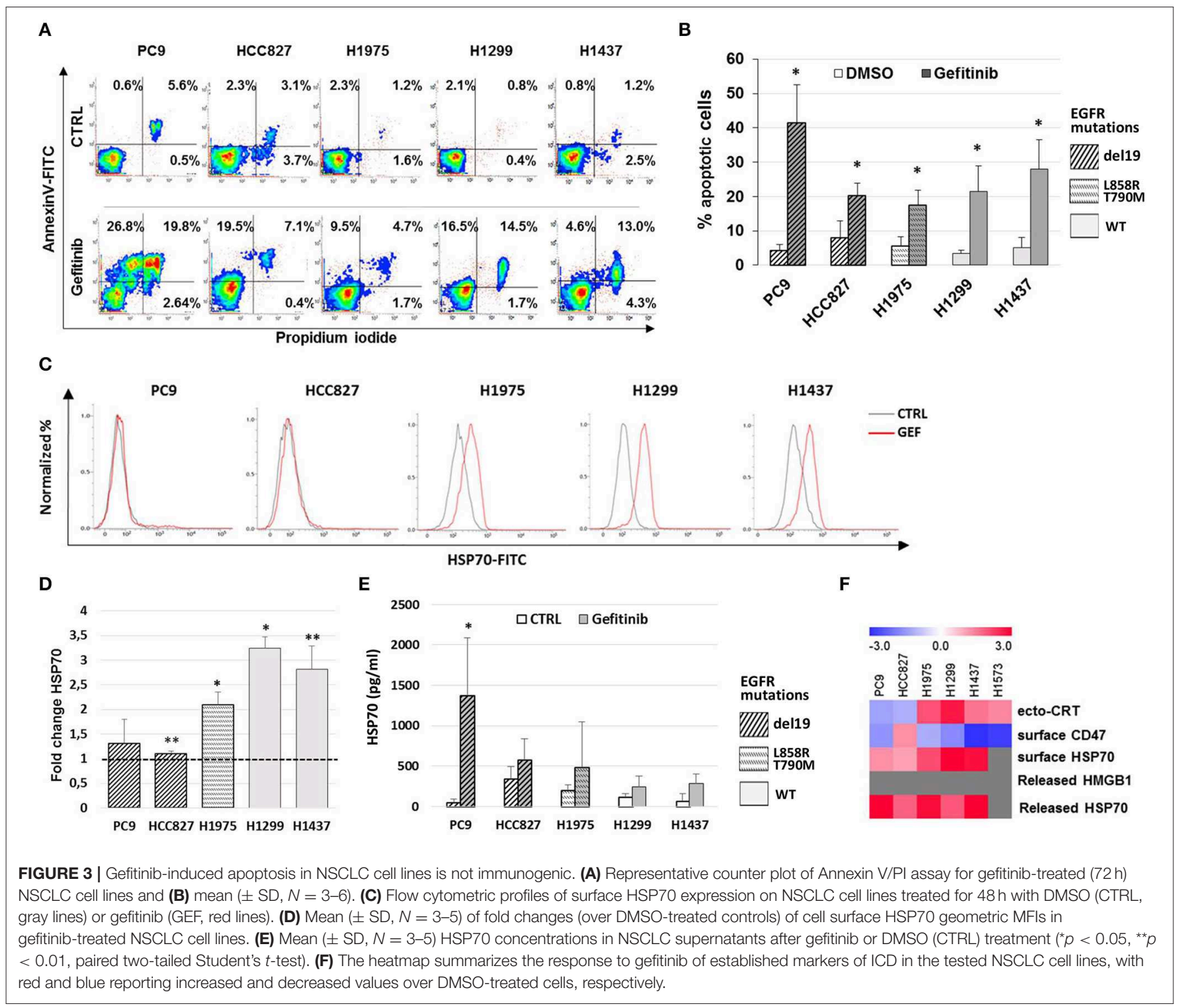

HCC827GR relative to the parental cell lines (Figure 6A). Conversely, the development of gefitinib resistance was not associated with higher expression of CRT on the plasma membrane (Figure 6B). As expected, treatment of PC9GR and HCC827GR cells with gefitinib for $48 \mathrm{~h}$ did not affect the expression levels of CD47 (Figure 6C) and failed to promote tumor cell phagocytosis by dendritic cells (Figure 6D). In contrast, blockade of the CD47/SIRP $\alpha$ axis by the addition of a CD47-specific mAb significantly increased PC9GR phagocytosis by dendritic cells in the presence or absence of gefitinib (Figure 6E).

\section{DISCUSSION}

Our study presents compelling evidence supporting the modulation of CD47 as a novel and important determinant of antitumor immunity in the response to EGFR TKI target therapy. In particular, our findings of overexpressed CD47 in transcriptomic analysis of patients with EGFR-mutated NSCLC, as well as in tumor cell lines acquiring EGFR TKI resistance, identify CD47 as target to be further explored for the immunotherapy treatment of naïve and resistant EGFR-mutant NSCLCs.

The development of resistance occurs consistently in patients affected by EGFR-mutant NSCLCs following first-line treatment with gefitinib and other TKIs. Secondary mutations in the EGFR gene, including T790M, account for more than $50 \%$ of resistant cases, followed by the MET gene amplification and the activation of other parallel pathways (41-43). In addition, histological transformation to SCLC may occur in 3-10\% of cases (11). Recently, the European Medicines Agency extended the approval of immunotherapy with ICIs to EGFR- and ALKpositive tumors after failure of appropriate targeted therapy. 


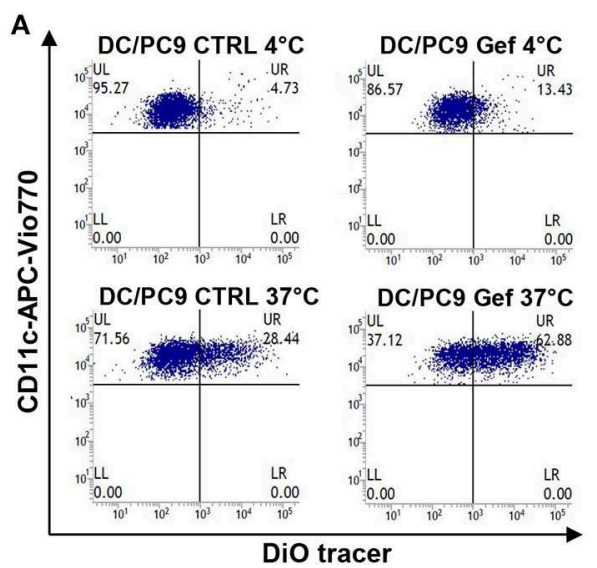

C

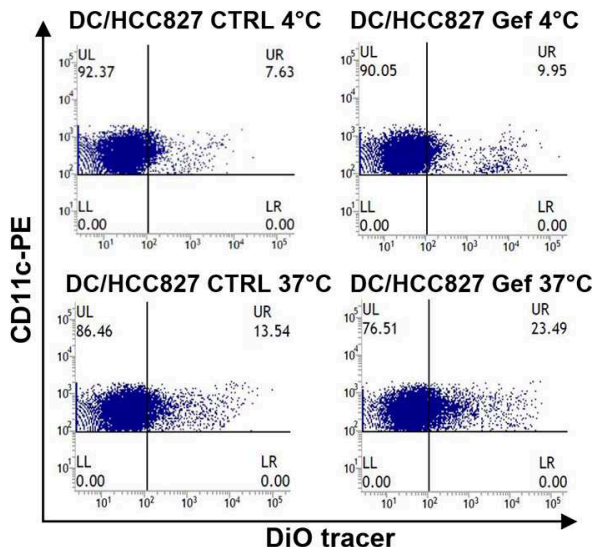

E

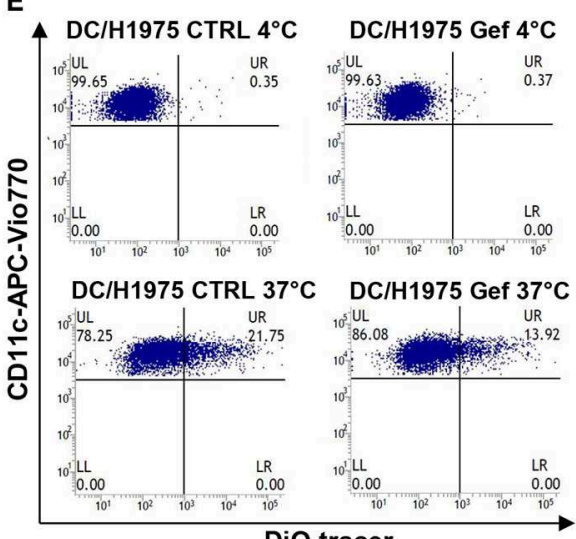

B

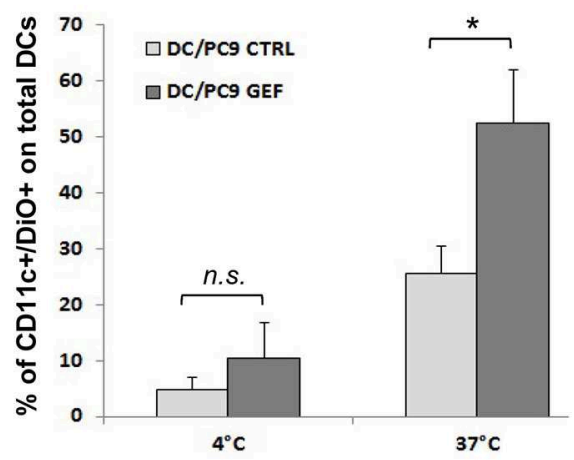

D

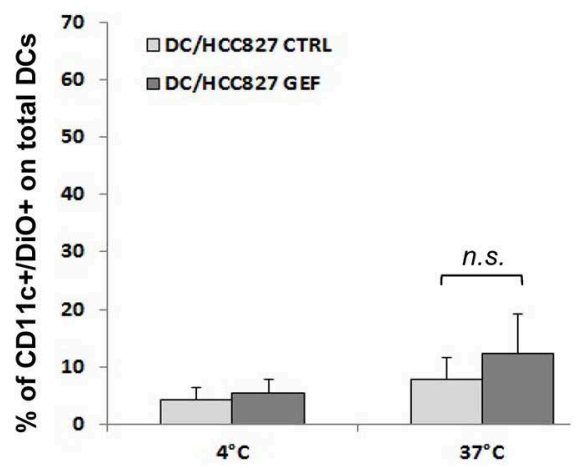

$\mathbf{F}$

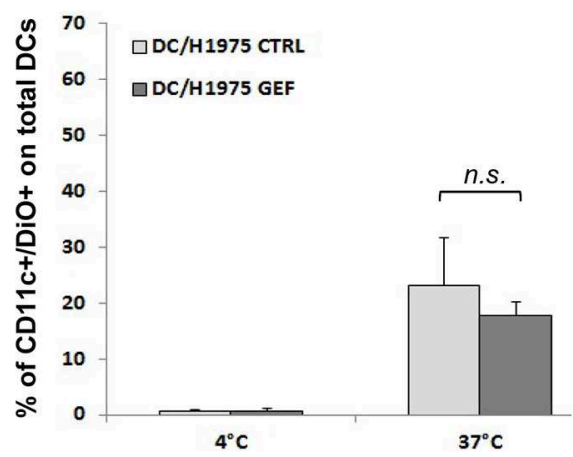

FIGURE 4 | Gefitinib-induced CD47 down-regulation promotes tumor cell phagocytosis by dendritic cells. Representative flow cytometric analyses and mean \pm SD ( $N=4$ independent healthy donors) of phagocytic activity of monocyte-derived dendritic cells (see Methods) against PC9 (A,B), HCC827 (C,D), and H1975 cells (E,F) treated with DMSO (CTRL) or gefitinib (GEF) as indicated. Cancer cells exposed to the drug for $48 \mathrm{~h}$ were labeled with DiO tracer and then co-cultured with dendritic cells for $2 \mathrm{~h}$ at a 1:1 ratio. Phagocytosis assays were also run at $4^{\circ} \mathrm{C}$ as controls. Histograms represent the percentages of positive cells for both $\mathrm{CD} 11 \mathrm{c}$ and DiO tracer relative to total dendritic cells ( ${ }^{*} p<0.05$, n.s., not significant, paired two-tailed Student's $t$-test).

However, the response of these patients to ICI therapy remains poor (13-15), indicating that blocking the PD1/PD-L1 axis is not sufficient to obtain an adequate antitumor immune response.
Several studies documented that first-generation EGFR TKIs improve the interaction between natural killer (NK) and tumor cells favoring immune-mediated cytotoxicity, indicating 


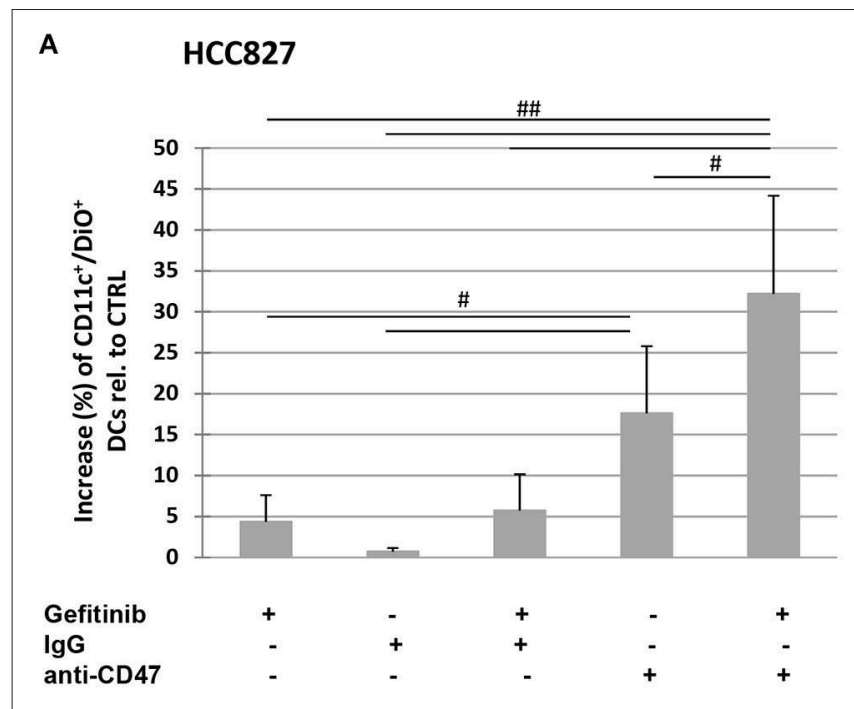

B

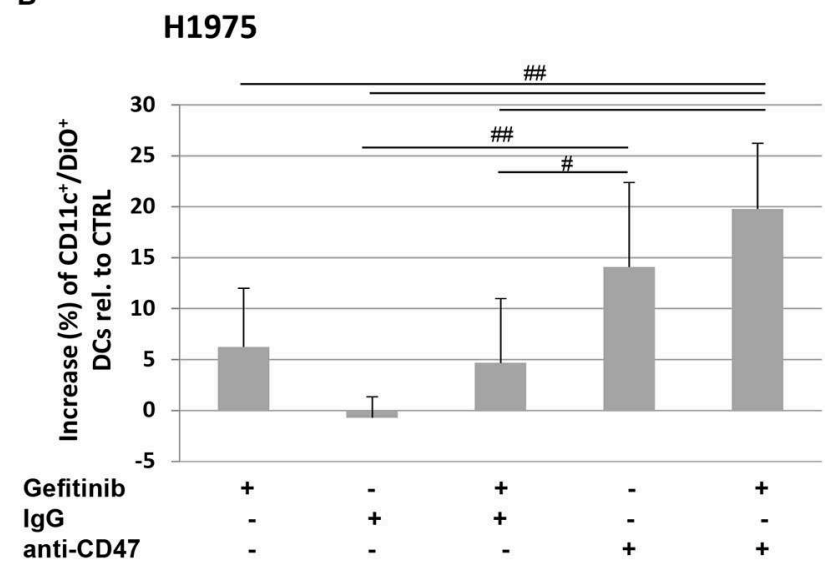

FIGURE 5 | Blocking of CD47 on tumor cells induces phagocytosis by dendritic cells. Dendritic cells were co-cultured with DiO tracer-labeled HCC827 (A) and H1975 (B) cancer cells in the presence of lgG isotype control or anti-CD47 mAb as indicated. Shown is the mean $( \pm \mathrm{SD}, N=3$

independent healthy donors) percentage increase of CD11c/DiO tracer double positive cells, relative to dendritic cells co-cultured with DMSO-treated tumor cells (\# $p<0.05$, \#\# $p<0.01$, ANOVA with Fisher's post hoc analysis).

that EGFR inhibitors can enhance innate tumor immune surveillance (44-46). Despite that, the potential impact of this therapy on immune recognition and elimination of cancer cells by phagocytes remains underexplored. Disruption of the CD47/SIRP $\alpha$ axis with specific mAbs may promote cancer cell elimination by macrophages, and it is a potential immunotherapeutic strategy recently described for different cancers, including SCLC and NSCLC (24, 26, 47-49). Our analysis of large transcriptomic dataset identified higher expression levels of CD47 mRNA, but not of CRT mRNA, in primary lung adenocarcinomas with EGFR mutations as compared to those with different oncogenic mutations. Functional relevance of CD47 overexpression is indicated by our data; although gefitinib down-regulates CD47 and increases
ecto-CRT in almost all cell lines tested, it is the decrement of CD47 that results in enhanced phagocytosis of cancer cells by dendritic cells. These results suggest that gefitinib could enhance antitumor immunity by improving lung cancer cell recognition and engulfment by immune phagocytes chiefly through CD47 down-regulation, thereby inhibiting tumor cell viability not only through TK-dependent mechanisms but also by enhancing innate anticancer immune responses.

At variance with previous works using anti-EGFR mAbs $7 \mathrm{~A} 7 \mathrm{~F}\left(\mathrm{ab}^{\prime}\right)_{2}$ in mice (50) and cetuximab in humans (36), in our experimental system, gefitinib does not induce ICD, as it fails to induce established ICD markers (e.g. HMGB1 secretion) in the cells where it promotes widespread apoptosis. Moreover, our results show that the activation of type I IFN pathway is not sufficient to improve the immunogenic features of gefitinib-induced apoptosis. On the other hand, the induction of HSP70 surface exposure and its release by gefitinib-treated tumor cells point to additional immune-modulatory effects of the EGFR TKI.

Our findings that gefitinib-induced down-regulation of CD47 promotes cancer cell phagocytosis in responsive cells and that establishment of gefitinib resistance reverts this response indicate a novel immune mechanism for EGFR TKI therapy, warranting further validation in preclinical and clinical studies. The relevance of CD47 as target in this setting is also underscored by the data obtained in PC9GR cells and in H1975 cells, which harbor a T790M mutation, showing that blocking the CD47/SIRP1 $\alpha$ axis promotes cancer cell elimination by dendritic cells also in NSCLC cell lines in which gefitinib has minimal or no effect on CD47 expression. On these bases, evaluation of CD47 expression in patients with EGFR-mutant NSCLCs becoming resistant to target therapy may justify the subsequent adoption of CD47-targeting immunotherapeutic options. In support of this strategy, the administration of CD47-specific mAb inhibited in vivo the growth of xenografted tumors developed from patient-derived lung cancer cells or cancer stem cells by recruiting macrophages into the tumor microenvironment (49). Moreover, the administration of CD47-blocking antibodies or targeted inactivation of the $C d 47$ gene in humanized mouse models markedly inhibited SCLC tumor growth (24). These evidences could support immunotherapy with CD47-blocking agents as a viable option also in patients undergoing histopathological transformation after EGFR-TKI therapy.

\section{CONCLUSIONS}

Several studies conducted over the last few years support an important role of the tumor microenvironment in mutant NSCL adenocarcinoma, especially in TKI resistance development and its dynamic remodeling by target therapy. Increasing awareness of an essential contribution by innate immunity in tumor immune surveillance and in metastasis control is advocated whereby new immunotherapeutic options are becoming available for management of relapsed EGFR mutant patients. In particular, promotion of tumor 
A

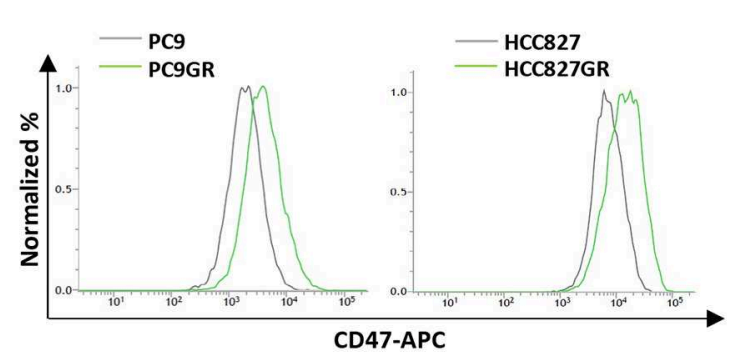

B

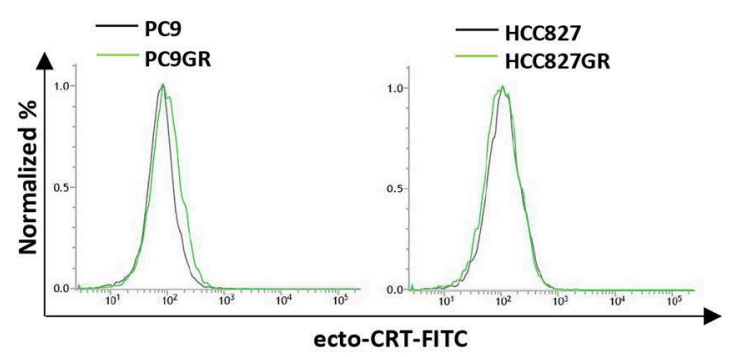

C

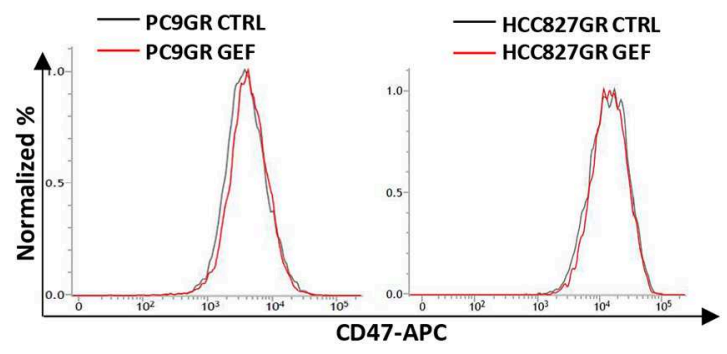

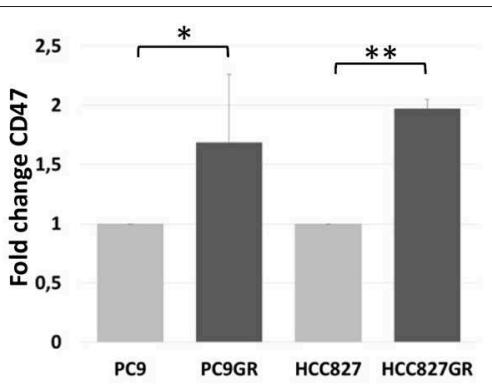
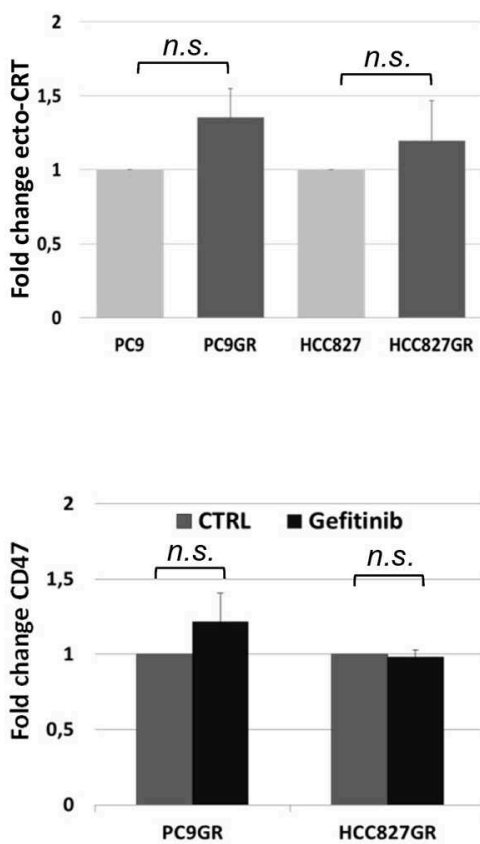

D

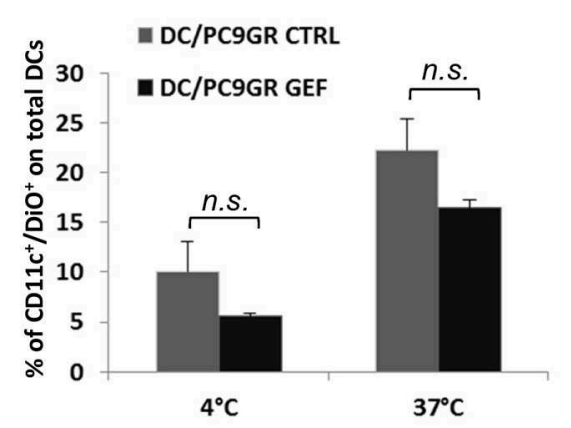

E

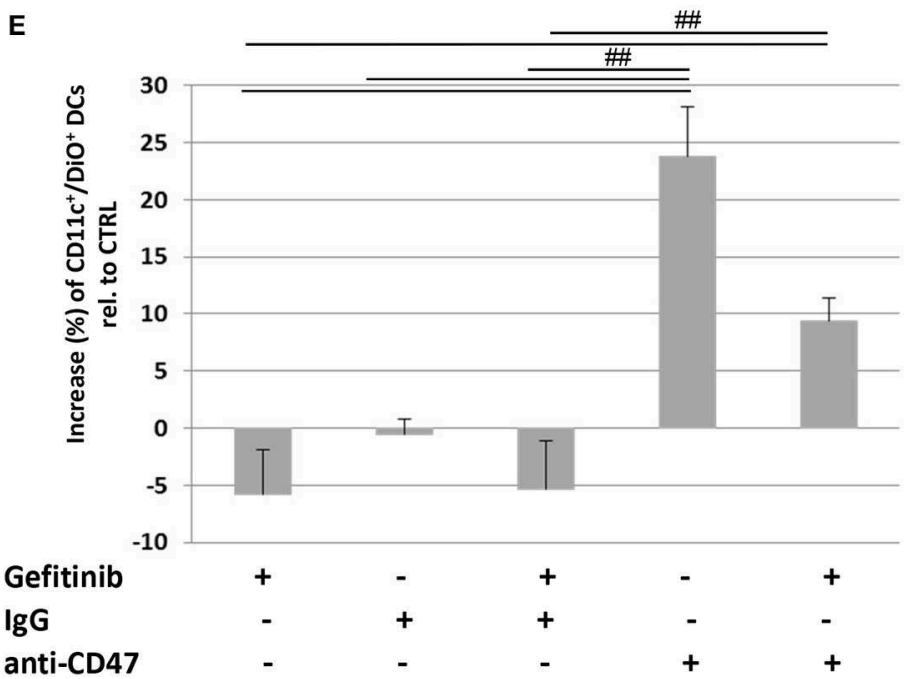

FIGURE 6 | Expression levels of surface CD47 increase in cancer cells acquiring resistance to gefitinib and inhibit tumor cell phagocytosis by dendritic cells. Surface CD47 (A) and ecto-CRT expression (B) in gefitinib-sensitive PC9 and HCC827 (gray lines) and resistant PC9GR and HCC827GR (green lines) cell lines. Representative flow cytometric histograms (left) and mean ( $\pm \mathrm{SD}, N=3-5$ ) fold changes of treatment-resistant over sensitive cells (right). (C) Representative flow cytometric histogram plots (left) and mean ( \pm SD) fold changes (right) of surface CD47 levels in resistant cell lines treated with DMSO (CTRL) or gefitinib (GEF) as indicated. 
FIGURE 6 | Acquisition of resistance to gefitinib abolished drug-induced CD47 down-regulation in PC9GR $\left({ }^{\star} p<0.05,{ }^{* *} p<0.01\right.$, n.s., not significant, paired two-tailed Student's $t$-test). (D) Mean \pm SD ( $N=3$ independent healthy donors) of phagocytic activity of monocyte-derived dendritic cells against PC9GR cells in the absence or presence of gefitinib treatment, performed at $4{ }^{\circ} \mathrm{C}$ as control and at $37^{\circ} \mathrm{C}$. Histograms represent the percentages of positive cells for both $\mathrm{CD} 11 \mathrm{C}$ and DiO tracer relative to total dendritic cells (paired two-tailed Student's $t$-test. n.s., not significant). (E) Dendritic cells were co-cultured with gefitinib-treated, DiO tracer-labeled PC9GR cells in the presence of lgG isotype control or anti-CD47 mAb. Shown is the mean $\pm \mathrm{SD}\left(N=3\right.$ independent healthy donors) percent change of CD11 $\mathrm{C}^{+} / \mathrm{DiO} \mathrm{O}^{+}$ tracer double positive dendritic cells, relative to dendritic cells co-cultured with DMSO-treated tumor cells (\#\# $p<0.01$, ANOVA with Fisher's post hoc analysis).

cells elimination by phagocytosis could be successfully achieved through the administration of anti-CD47 mAbs. The effectiveness of CD47 blockade also following gefitinib treatment, as shown in our experiments in vitro, supports the development of therapeutic strategies in which anti-CD47 immunotherapy and target therapy may be combined to minimize the development of resistant clones responsible for tumor relapse.

\section{DATA AVAILABILITY STATEMENT}

The raw data supporting the conclusions of this article will be made available by the authors, without undue reservation, to any qualified researcher.

\section{AUTHOR CONTRIBUTIONS}

AN performed most of the experiments, analyzed the data, and drafted the figures and parts of the manuscript. LR provided support with the statistical analysis and performed in silico analyses. IS, MV, and MC performed some of the experiments and analyzed the data. BM helped set up phagocytosis assays. FS, SP, and MT critically revised the manuscript. CS made significant contributions to data interpretation, manuscript writing, and revision. VC conceived and supervised the study and critically revised the manuscript. JDC conceived the study, developed the experimental design, analyzed and interpreted the data, and wrote the manuscript. All authors contributed

\section{REFERENCES}

1. Molina JR, Yang P, Cassivi SD, Schild SE, Adjei AA. Non-small cell lung cancer: epidemiology, risk factors, treatment, and survivorship. Mayo Clin Proc. (2008) 83:584-94. doi: 10.4065/83.5.584

2. Bender E. Epidemiology: the dominant malignancy. Nature. (2014) 513:S2-3. doi: $10.1038 / 513$ S2a

3. Russo A, Franchina T, Ricciardi GRR, Smiroldo V, Picciotto M, Zanghi M, et al. Third generation EGFR TKIs in EGFR-mutated NSCLC: where are we now and where are we going. Crit Rev Oncol Hematol. (2017) 117:38-47. doi: 10.1016/j.critrevonc.2017.07.003

4. Bivona TG, Doebele RC. A framework for understanding and targeting residual disease in oncogene-driven solid cancers. Nat Med. (2016) 22:472-8. doi: $10.1038 / \mathrm{nm} .4091$

5. Rotow J, Bivona TG. Understanding and targeting resistance mechanisms in NSCLC. Nat Rev Cancer. (2017) 17:637-58. doi: 10.1038/nrc. 2017.84

6. Im JS, Herrmann AC, Bernatchez C, Haymaker C, Molldrem JJ, Hong WK, et al. Immune-modulation by epidermal growth factor receptor inhibitors: implication on anti-tumor immunity in lung cancer. PLoS ONE. (2016) 11:e0160004. doi: 10.1371/journal.pone.0160004 toward drafting and revising the paper and approved the final manuscript.

\section{FUNDING}

The work was supported by Fondazione con il Sud (Grant: Brains2South 2015 PDR-0224 to JDC), POR Campania FESR 2007-2013-RETE DELLE BIOTECNOLOGIE IN CAMPANIA-Project Terapie Innovative di Malattie Infiammatorie croniche, metaboliche, Neoplastiche e Geriatriche-TIMING (to CS), and FARB 2017/2018 (to CS and VC), Regione Campania, POR FESR 2014/20 RarePlatNet Project (Az. 1.2, CUP B63D18000380007) (to VC).

\section{ACKNOWLEDGMENTS}

The authors thank Prof. Normanno's lab (Cell Biology and Biotherapy Unit, Istituto Nazionale Tumori di Napoli, IRCCS G. Pascale) for the kind gift of PC9 and HCC827 cell lines and Dr. G. Giurato (Department of Medicine, Surgery and Dentistry Scuola Medica Salernitana, University of Salerno) for kind assistance in analysis of the microarray dataset.

\section{SUPPLEMENTARY MATERIAL}

The Supplementary Material for this article can be found online at: https://www.frontiersin.org/articles/10.3389/fimmu. 2019.03135/full\#supplementary-material

7. Yao Z, Fenoglio S, Gao DC, Camiolo M, Stiles B, Lindsted T, et al. TGF-beta IL6 axis mediates selective and adaptive mechanisms of resistance to molecular targeted therapy in lung cancer. Proc Natl Acad Sci USA. (2010) 107:15535-40. doi: 10.1073/pnas.1009472107

8. Akbay EA, Koyama S, Carretero J, Altabef A, Tchaicha JH, Christensen $\mathrm{CL}$, et al. Activation of the PD-1 pathway contributes to immune escape in EGFR-driven lung tumors. Cancer Discov. (2013) 3:1355-63. doi: 10.1158/2159-8290.CD-13-0310

9. Su S, Dong ZY, Xie Z, Yan LX, Li YF, Su J, et al. Strong programmed death ligand 1 expression predicts poor response and de novo resistance to EGFR tyrosine kinase inhibitors among NSCLC patients with EGFR mutation. J Thorac Oncol. (2018) 13:1668-75. doi: 10.1016/j.jtho.2018. 07.016

10. Choe C, Shin YS, Kim C, Choi SJ, Lee J, Kim SY, et al. Crosstalk with cancerassociated fibroblasts induces resistance of non-small cell lung cancer cells to epidermal growth factor receptor tyrosine kinase inhibition. Onco Targets Ther. (2015) 8:3665-78. doi: 10.2147/OTT.S89659

11. Remon J, Ahn MJ, Girard N, Johnson M, Kim DW, Lopes G, et al. Advanced-stage non-small cell lung cancer: advances in thoracic oncology 2018. J Thorac Oncol. (2019) 14:1134-55. doi: 10.1016/j.jtho.2019. 03.022 
12. Tabchi S, Kourie HR, Kattan J. Adding checkpoint inhibitors to tyrosine kinase inhibitors targeting EGFR/ALK in non-small cell lung cancer: a new therapeutic strategy. Invest New Drugs. (2016) 34:794-6. doi: 10.1007/s10637-016-0383-2

13. Garassino MC, Cho BC, Kim JH, Mazieres J, Vansteenkiste J, Lena H, et al. Durvalumab as third-line or later treatment for advanced nonsmall-cell lung cancer (ATLANTIC): an open-label, single-arm, phase 2 study. Lancet Oncol. (2018) 19:521-36. doi: 10.1016/S1470-2045(18) 30144-X

14. Garassino MC, Gelibter AJ, Grossi F, Chiari R, Soto Parra H, Cascinu $\mathrm{S}$, et al. Italian nivolumab expanded access program in nonsquamous non-small cell lung cancer patients: results in never-smokers and EGFRmutant patients. J Thorac Oncol. (2018) 13:1146-55. doi: 10.1016/j.jtho.2018. 04.025

15. Mazieres J, Drilon A, Lusque A, Mhanna L, Cortot AB, Mezquita L, et al. Immune checkpoint inhibitors for patients with advanced lung cancer and oncogenic driver alterations: results from the IMMUNOTARGET registry. Ann Oncol. (2019) 30:1321-8. doi: 10.1093/annonc/ mdz167

16. Cho JH, Jung HA, Lee SH, Ahn JS, Ahn MJ, Park K, et al. Impact of EGFR mutation on the clinical efficacy of PD-1 inhibitors in patients with pulmonary adenocarcinoma. J Cancer Res Clin Oncol. (2019) 145:1341-9. doi: 10.1007/s00432-019-02889-0

17. Barclay AN, Van den Berg TK. The interaction between signal regulatory protein alpha (SIRPalpha) and CD47: structure, function, and therapeutic target. Annu Rev Immunol. (2014) 32:25-50. doi: 10.1146/annurev-immunol-032713-120142

18. Brown EJ, Frazier WA. Integrin-associated protein (CD47) and its ligands. Trends Cell Biol. (2001) 11:130-5. doi: 10.1016/S0962-8924(00) 01906-1

19. Chao MP, Weissman IL, Majeti R. The CD47-SIRPalpha pathway in cancer immune evasion and potential therapeutic implications. Curr Opin Immunol. (2012) 24:225-32. doi: 10.1016/j.coi.2012.01.010

20. Oldenborg PA, Zheleznyak A, Fang YF, Lagenaur CF, Gresham HD, Lindberg FP. Role of CD47 as a marker of self on red blood cells. Science. (2000) 288:2051-4. doi: 10.1126/science.288.5473.2051

21. Jaiswal S, Jamieson CH, Pang WW, Park CY, Chao MP, Majeti R, et al. CD47 is upregulated on circulating hematopoietic stem cells and leukemia cells to avoid phagocytosis. Cell. (2009) 138:271-85. doi: 10.1016/j.cell.2009. 05.046

22. Willingham SB, Volkmer JP, Gentles AJ, Sahoo D, Dalerba P, Mitra SS, et al. The CD47-signal regulatory protein alpha (SIRPa) interaction is a therapeutic target for human solid tumors. Proc Natl Acad Sci USA. (2012) 109:6662-7. doi: $10.1073 /$ pnas. 1121623109

23. Uluckan O, Becker SN, Deng H, Zou W, Prior JL, Piwnica-Worms D, et al. CD47 regulates bone mass and tumor metastasis to bone. Cancer Res. (2009) 69:3196-204. doi: 10.1158/0008-5472.CAN-08-3358

24. Weiskopf K, Jahchan NS, Schnorr PJ, Cristea S, Ring AM, Maute RL, et al. CD47-blocking immunotherapies stimulate macrophage-mediated destruction of small-cell lung cancer. J Clin Invest. (2016) 126:2610-20. doi: 10.1172/JCI81603

25. Zhao H, Wang J, Kong X, Li E, Liu Y, Du X, et al. CD47 Promotes tumor invasion and metastasis in non-small cell lung cancer. Sci Rep. (2016) 6:29719. doi: $10.1038 /$ srep29719

26. Zhang X, Fan J, Wang S, Li Y, Wang Y, Li S, et al. Targeting CD47 and autophagy elicited enhanced antitumor effects in non-small cell lung cancer. Cancer Immunol Res. (2017) 5:363-75. doi: 10.1158/2326-6066.CIR16-0398

27. Kong F, Gao F, Li H, Liu H, Zhang Y, Zheng R, et al. CD47: a potential immunotherapy target for eliminating cancer cells. Clin Transl Oncol. (2016) 18:1051-5. doi: 10.1007/s12094-016-1489-x

28. Weiskopf K. Cancer immunotherapy targeting the CD47/SIRPalpha axis. Eur J Cancer. (2017) 76:100-9. doi: 10.1016/j.ejca.2017.02.013

29. Montico B, Lapenta C, Ravo M, Martorelli D, Muraro E, Zeng B, et al. Exploiting a new strategy to induce immunogenic cell death to improve dendritic cell-based vaccines for lymphoma immunotherapy. Oncoimmunology. (2017) 6:e1356964. doi: 10.1080/2162402X.2017. 1356964
30. Obeid M, Tesniere A, Panaretakis T, Tufi R, Joza N, van Endert P, et al. Ectocalreticulin in immunogenic chemotherapy. Immunol Rev. (2007) 220:22-34. doi: 10.1111/j.1600-065X.2007.00567.x

31. Fucikova J, Becht E, Iribarren K, Goc J, Remark R, Damotte D, et al. Calreticulin expression in human non-small cell lung cancers correlates with increased accumulation of antitumor immune cells and favorable prognosis. Cancer Res. (2016) 76:1746-56. doi: 10.1158/0008-5472.CAN-15-1142

32. Santini SM, Lapenta C, Santodonato L, D'Agostino G, Belardelli F, Ferrantini M. IFN-alpha in the generation of dendritic cells for cancer immunotherapy. Handb Exp Pharmacol. (2009) 188:295-317. doi: 10.1007/978-3-540-71029-5_14

33. Okayama H, Kohno T, Ishii Y, Shimada Y, Shiraishi K, Iwakawa $\mathrm{R}$, et al. Identification of genes upregulated in ALK-positive and EGFR/KRAS/ALK-negative lung adenocarcinomas. Cancer Res. (2012) 72:100-11. doi: 10.1158/0008-5472.CAN-11-1403

34. Yamauchi M, Yamaguchi R, Nakata A, Kohno T, Nagasaki M, Shimamura $\mathrm{T}$, et al. Epidermal growth factor receptor tyrosine kinase defines critical prognostic genes of stage I lung adenocarcinoma. PLoS ONE. (2012) 7:e43923. doi: 10.1371/journal.pone.0043923

35. Li Q, Birkbak NJ, Gyorffy B, Szallasi Z, Eklund AC. Jetset: selecting the optimal microarray probe set to represent a gene. BMC Bioinformatics. (2011) 12:474. doi: 10.1186/1471-2105-12-474

36. Pozzi C, Cuomo A, Spadoni I, Magni E, Silvola A, Conte A, et al. The EGFR-specific antibody cetuximab combined with chemotherapy triggers immunogenic cell death. Nat Med. (2016) 22:624-31. doi: 10.1038/ nm.4078

37. Kepp O, Senovilla L, Vitale I, Vacchelli E, Adjemian S, Agostinis $\mathrm{P}$, et al. Consensus guidelines for the detection of immunogenic cell death. Oncoimmunology. (2014) 3:e955691. doi: 10.4161/21624011.2014. 955691

38. Liu P, Zhao L, Pol J, Levesque S, Petrazzuolo A, Pfirschke C, et al. Author correction: crizotinib-induced immunogenic cell death in non-small cell lung cancer. Nat Commun. (2019) 10:1883. doi: 10.1038/s41467-01909838-y

39. Sistigu A, Yamazaki T, Vacchelli E, Chaba K, Enot DP, Adam J, et al. Cancer cell-autonomous contribution of type I interferon signaling to the efficacy of chemotherapy. Nat Med. (2014) 20:1301-9. doi: 10.1038/nm. 3708

40. Cox MC, Castiello L, Mattei M, Santodonato L, D’Agostino G, Muraro E, et al. Clinical and antitumor immune responses in relapsed/refractory follicular lymphoma patients after intranodal injections of IFN $\alpha$-dendritic cells and Rituximab: a phase I clinical trial. Clin Cancer Res. (2019) 25:5231-41. doi: 10.1158/1078-0432.CCR-19-0709

41. Yu HA, Arcila ME, Rekhtman N, Sima CS, Zakowski MF, Pao W, et al. Analysis of tumor specimens at the time of acquired resistance to EGFR-TKI therapy in 155 patients with EGFR-mutant lung cancers. Clin Cancer Res. (2013) 19:2240-7. doi: 10.1158/1078-0432.CCR-12-2246

42. Lee CK, Kim S, Lee JS, Lee JE, Kim SM, Yang IS, et al. Next-generation sequencing reveals novel resistance mechanisms and molecular heterogeneity in EGFR-mutant non-small cell lung cancer with acquired resistance to EGFR-TKIs. Lung Cancer. (2017) 113:106-14. doi: 10.1016/j.lungcan.2017. 09.005

43. Kosaka T, Yatabe Y, Endoh H, Yoshida K, Hida T, Tsuboi M, et al. Analysis of epidermal growth factor receptor gene mutation in patients with non-small cell lung cancer and acquired resistance to gefitinib. Clin Cancer Res. (2006) 12:5764-9. doi: 10.1158/1078-0432.CCR-06-0714

44. Dominguez C, Tsang KY, Palena C. Short-term EGFR blockade enhances immune-mediated cytotoxicity of EGFR mutant lung cancer cells: rationale for combination therapies. Cell Death Dis. (2016) 7:e2380. doi: 10.1038/cddis.2016.297

45. He S, Yin T, Li D, Gao X, Wan Y, Ma X, et al. Enhanced interaction between natural killer cells and lung cancer cells: involvement in gefitinib-mediated immunoregulation. J Transl Med. (2013) 11:186. doi: 10.1186/1479-5876-11-186

46. Kim H, Kim SH, Kim MJ, Kim SJ, Park SJ, Chung JS, et al. EGFR inhibitors enhanced the susceptibility to NK cell-mediated lysis of lung cancer cells. J Immunother. (2011) 34:372-81. doi: 10.1097/CJI.0b013e318 $21 \mathrm{~b} 724 \mathrm{a}$ 
47. Feng M, Jiang W, Kim BYS, Zhang CC, Fu YX, Weissman IL. Phagocytosis checkpoints as new targets for cancer immunotherapy. Nat Rev Cancer. (2019) 19:568-86. doi: 10.1038/s41568-0190183-z

48. Orozco-Morales M, Soca-Chafre G, Barrios-Bernal P, Hernandez-Pedro N, Arrieta O. Interplay between cellular and molecular inflammatory mediators in lung cancer. Mediators Inflamm. (2016) 2016:3494608. doi: 10.1155/2016/34 94608

49. Liu L, Zhang L, Yang L, Li H, Li R, Yu J, et al. Anti-CD47 Antibody as a targeted therapeutic agent for human lung cancer and cancer stem cells. Front Immunol. (2017) 8:404. doi: 10.3389/fimmu.2017. 00404

50. Garrido G, Rabasa A, Sanchez B, Lopez MV, Blanco R, Lopez A, et al. Induction of immunogenic apoptosis by blockade of epidermal growth factor receptor activation with a specific antibody. J Immunol. (2011) 187:4954-66. doi: $10.4049 /$ jimmunol.1003477

Conflict of Interest: The authors declare that the research was conducted in the absence of any commercial or financial relationships that could be construed as a potential conflict of interest.

Copyright (C) 2020 Nigro, Ricciardi, Salvato, Sabbatino, Vitale, Crescenzi, Montico, Triggiani, Pepe, Stellato, Casolaro and Dal Col. This is an open-access article distributed under the terms of the Creative Commons Attribution License (CC BY). The use, distribution or reproduction in other forums is permitted, provided the original author(s) and the copyright owner(s) are credited and that the original publication in this journal is cited, in accordance with accepted academic practice. No use, distribution or reproduction is permitted which does not comply with these terms. 